\title{
CORRIDA PERIÓDICA: DESMISTIFICANDO A LINGUAGEM CIENTÍFICA DOS ELEMENTOS QUÍMICOS
}

\section{PERIODIC RACE: DEMISTIFYING THE SCIENTIFIC LANGUAGE OF THE CHEMICAL ELEMENTS}

\author{
Renata Joaquina de Oliveira Barboza ${ }^{1}$; Ayrton Matheus da Silva Nascimento²; Magadã \\ Marinho Rocha de Lira ${ }^{3}$
}

\section{RESUMO}

A linguagem científica escolar na disciplina de química é repleta de símbolos, fórmulas e representações que retratam os conhecimentos químicos descritos em materiais e recursos didáticos utilizados por professores e estudantes. Como falamos em linguagem, é interessante citarmos os estudos de Vygotsky que apontam a importância da utilização da linguagem no processo de interação social e construção de conhecimento. Nesta perspectiva, evidenciamos os jogos didáticos como uma atividade que promove a apropriação da linguagem científica escolar em química e que contribuem para a participação dos estudantes na aula. Assim, o estudo tem o objetivo de analisar o papel do jogo didático Corrida Periódica na apropriação da simbologia característica do conteúdo de Tabela Periódica. Trata-se de uma pesquisa qualitativa realizada em duas turmas da $1^{\mathrm{a}}$ série do Ensino Médio de uma Escola de Referência em ensino Médio na cidade de Salgadinho-PE. O jogo foi proposto pelos pesquisadores e aplicado pelo professor das turmas. Utilizamos como instrumentos o diário de campo do pesquisador e entrevistas com alguns estudantes. $\mathrm{Na}$ análise dos dados produzidos, evidenciamos as interações entre o professor e os estudantes no jogo e os pontos de vistas dos estudantes na entrevista. No decorrer do jogo percebemos que os estudantes conheciam apenas os elementos químicos mais vistos em seu dia-a-dia e apresentaram bastante dificuldade nas propriedades periódicas, além de não conhecer a importância da simbologia deste conteúdo. A partir do jogo, os estudantes conseguiram ter o contato direto com a Tabela Periódica, a conhecendo de fato e desmistificando aos poucos a linguagem presente nela, compreendendo que ela traz uns conhecimentos embasados em estudos e que contribui efetivamente para diversos conteúdos químicos. Portanto, o uso de atividades como o jogo didático proporciona um ambiente propício a essa apropriação da linguagem científica escolar na disciplina de química, assim como o aprendizado dos significados que desmistificam a linguagem química dos conteúdos.

Palavras-Chave: Ensino de química, Jogo didático, Linguagem científica escolar.

\section{ABSTRACT}

The school scientific language in the chemistry content is full of symbols, formulas and representations that shows the chemical knowledge described in materials and didactic resources used by teachers and students. As we speak in language, it is interesting to write about Vygotsky's studies that point out the importance of the use of language in the process of social interaction and construction of knowledge. In this perspective, we show the didactic games as an activity that promotes the appropriation of the scientific school language in chemistry and

\footnotetext{
1 Mestranda em Educação de Ciências e Matemática, Universidade Federal de Pernambuco - Centro Acadêmico do Agreste, renata_joaquina@hotmail.com

2 Especialista em Ensino de química, Universidade Candido Mendes - UCAM PROMINAS, ayrthon.matheus@gmail.com

3 Doutora em Educação, Instituto Federal de Pernambuco - Campus Vitória de Santo Antão, magada.lira@vitoria.ifpe.edu.br
} 
that contribute to the students' participation in the class. Thus, the study has the objective of analyzing the role of the didactic game Periodic Race in the appropriation of the symbology characteristic of the content of Periodic Table. This is a qualitative research carried out in two classes in grade 10 at a Secondary School in Salgadinho-PE. The game was proposed by the researchers and applied by the class teacher. We used as instruments the researcher's field diary and interviews with some students. In the analysis of the data produced, we show the interactions between the teacher and the students in the game and the points of view of the students in the interview. In the course of the game we noticed that the students knew only the most commonly seen chemical elements in their daily life and they presented difficulties in the periodic properties, besides not knowing the importance of the symbology of this content. With the game, the students were able to have direct contact with the Periodic Table, knowing it properly and slowly demystifying the language present in it, understanding that it brings a knowledge based in studies and that effectively contributes to various chemistry contents. Therefore, the use of activities such as the didactic game provides an environment conducive to this appropriation of the scientific school language in chemistry, as well as learning the meanings that demystify the contents' chemistry language.

Keywords: Chemistry teaching, Didactic game, School scientific language

\section{INTRODUÇÃO}

A química é uma ciência que possui uma linguagem própria, caracterizada pelo uso de representações simbólicas nos conhecimentos químicos. Andrade Neto, Raupp e Moreira (2009) mencionam que a linguagem química é utilizada desde os alquimistas e artesões e foi inicialmente criada para tanto comunicar como para restringir a compreensão da linguagem aos iniciantes garantindo seu caráter oculto dentro da alquimia, e então, com o passar do tempo, surgiu a necessidade de uma unificação na forma de expressão para que a comunicação entre os químicos fosse viável, surgindo desta forma uma linguagem universal que é utilizada tanto entre os experts em química como em educação química atualmente.

$\mathrm{Na}$ educação em química, mas especificamente no Ensino Médio, os livros didáticos abordam os conteúdos de química com a linguagem característica desta ciência. Como exemplos Oliveira, Schlünzen Junior e Schlünzen (2013) citam que para os elementos químicos, usam-se os símbolos químicos, abreviação contendo até duas letras, do nome em latim ou grego, para representar a composição química das substâncias, são utilizados os símbolos químicos dos elementos, constituindo a linguagem química do material e para os compostos ou substâncias, de qualquer natureza, usam-se as fórmulas químicas.

Assim, para uma maior compreensão dos conhecimentos químicos, é necessário o entendimento desta linguagem circulante nos conteúdos de química. Contudo, algumas dificuldades são apresentadas ao discutirmos o ensino de química no Ensino Médio, e uma delas é exatamente compreender os significados da linguagem química e utilizá-los para a aprendizagem na disciplina, tornando-se um desafio para a prática docente.

Tomando essa realidade, os professores devem procurar utilizar atividades na sala de 
aula que auxiliem de fato os estudantes na compreensão da linguagem química e consequentemente na aprendizagem dos conteúdos abordados. Nesta perspectiva, evidenciamos o uso dos jogos didáticos no ambiente escolar como uma prática facilitadora e promovedora da apropriação da linguagem científica escolar dos conteúdos de química e que motivam e contribuem para a participação dos estudantes na aula.

Neste sentido, em um embasamento da psicologia histórico-cultural de Vygotsky, Messeder Neto e Moradillo (2017), apontam que a atmosfera lúdica proposta pelo jogo permite que o estudante se concentre mais no conteúdo, dirigindo seu foco para a discussão dos conceitos envolvidos na atividade, contudo não é qualquer jogo que favorece o desenvolvimento e a mobilização da atenção para o conteúdo de química: a atividade pensada e desenvolvida deve ter um conteúdo científico desafiador para o estudante, exigindo dele foco e raciocínio lógico.

Assim, ao tratar da linguagem química no jogo didático como base para aprendizagem dos conhecimentos químicos, viabiliza a curiosidade dos estudantes e os instiga a conhecerem a temática abordada para assim ter um bom desenvolvimento no jogo, o que favorece a aprendizagem. Desta forma, o estudo tem o objetivo de analisar o papel do jogo didático Corrida Periódica na apropriação da simbologia característica do conteúdo de Tabela Periódica.

\section{FUNDAMENTAÇÃO TEÓRICA}

Ao falarmos em linguagem, é interessante considerarmos os estudos de Vygotsky (2008) acerca da mediação e a importância da utilização da linguagem no processo de interação social, caracterizando a perspectiva de aprendizagem sociointeracionista proposta e defendida por ele. Desse modo, Fontana e Cruz (1997) descrevem que segundo a abordagem histórico-cultural relatada por Vygotsky, a relação entre homem e meio é sempre mediada por produtos culturais humanos, como o instrumento e o signo, e pelo 'outro'. Os sistemas de signos (a linguagem, a escrita, o sistema de números), e o sistema de instrumentos, são criados pelas sociedades ao longo da história humana e transformam a forma social e o nível de seu desenvolvimento cultural (VYGOTSKY, 2008).

De acordo com Oliveira (2002) as representações da realidade foram organizadas em sistemas simbólicos, no qual, os signos são compartilhados pelo grupo social, permitindo a comunicação, a interação e a organização do real, sendo a linguagem o sistema simbólico básico e mais importante de todos os grupos humanos, pois é por meio dela que os significados das palavras são um produto da história e da relação entre os homens, de acordo com a teoria de Vygotsky. 
A linguagem é toda composta de signos que nos possibilita a capacidade de construir representações mentais que substituam os objetos do mundo real, como exemplo pode-se citar a palavra cadeira que se remete ao objeto concreto cadeira, desse modo percebemos que você certamente pode imaginar uma agora mesmo sem a necessidade de vê-la, essa característica é um traço evolutivo importante, pois, proporciona libertar-se do espaço e do tempo presentes, fazer relações mentais na ausência das próprias coisas, fazer planos e ter intenções (OLIVEIRA, 2002; PIOVESAN, 2015).

Para a aquisição de conhecimentos, a mesma característica é fundamental, pois permite aprender por meio da experiência do outro (PIOVESAN, 2015). Por isso, a importância de existir a interação entre os indivíduos na potencialidade do processo de aprendizagem, ocorrendo assim a internalização do conhecimento. Vygotsky (2008) descreve que a aprendizagem acontece a partir da internalização, em que um processo interpessoal é transformado em um processo intrapessoal e uma vez internalizados esses processos tornam-se parte das aquisições do desenvolvimento.

Ao falarmos em apropriação de uma linguagem, destacamos que é um processo que se mostra a medida em que se é capaz de ler e escrever na linguagem própria desta cultura (FANG, 2006; SEPULVEDA et al., 2006). Como a química é uma ciência que faz extensivo uso de modelos, ou seja, representações simplificadas ou idealizadas do mundo real (DEL RE, 2000), é interessante que, a sala de aula seja um ambiente propício a apropriação desta linguagem característica, para dessa forma, viabilizar o processo de aprendizagem a partir da significação da linguagem e conceitos dos conteúdos.

Nesta perspectiva, o professor deve planejar suas aulas, incluindo atividades que proporcionem essa apropriação da linguagem científica escolar da química. Apontamos, assim, o uso dos jogos didáticos no ambiente escolar, uma vez que eles contribuem para a construção de conhecimento, por meio do elo do lúdico e do educativo, que incentiva a curiosidade e participação dos estudantes, proporcionando a interação necessária para a efetividade da atividade. Miranda (2001) destaca como fenômenos positivamente influenciados pela adoção de atividades lúdicas no cotidiano da sala de aula a cognição, a motivação, a socialização, a afeição e a criatividade.

O professor nesse caso tem o papel de mediador, possibilitando discussões e direcionando a aula a fim de um bom resultado. É importante descrever também que, ao planejar levar um jogo didático para a sala de aula, o professor considere as especificidades da turma, incluindo, faixa etária, características de comportamento, personalidade dos estudantes etc., para assim realizar uma boa escolha do tipo de jogo e criar um ambiente com a maior 
participação e interação possível por parte dos estudantes.

Conforme Vygotsky (2007), a contribuição dos jogos para a aprendizagem de conhecimentos escolares ou científicos ocorre a partir da interação e a atuação na Zona de Desenvolvimento Proximal (ZDP) dos estudantes que corresponde à distância entre o nível de desenvolvimento real, determinado a partir da solução independente de problemas, e o nível de desenvolvimento potencial, determinado a partir da solução de problemas sob a orientação de um adulto (professor) ou em colaboração com companheiros mais experientes.

\section{METODOLOGIA}

Trata-se de uma pesquisa qualitativa, realizada na disciplina de química de duas turmas da $1^{\text {a }}$ série do Ensino Médio de uma Escola de Referência em ensino Médio localizada na cidade de Salgadinho-PE. O jogo didático Corrida Periódica foi proposto pelos pesquisadores e aplicado pelo professor das turmas. O professor é licenciado em Química e atua como docente na Rede Estadual de Ensino desde março de 2017. Utilizamos como instrumentos o diário de campo do pesquisador e entrevistas com alguns estudantes.

As entrevistas foram realizadas com os estudantes após a aplicação do jogo didático, a fim de identificar as contribuições do jogo para a aprendizagem no conteúdo. Salientamos que foi escolhido um componente de cada equipe participante do jogo para ser entrevistado, como foram 4 (quatro) equipes, foram entrevistados 4 (quatro) estudantes. Assim, foi realizada duas entrevistas em grupo, uma em cada turma, totalizando 8 (oito) estudantes.

Para análise dos dados produzidos, procuramos evidenciar as interações entre o professor e os estudantes durante a atividade e os pontos de vistas observados na fala dos estudantes na entrevista de modo a identificar aspectos emergentes da apropriação da simbologia característica do conteúdo de Tabela Periódica.

\section{O jogo didático Corrida Periódica}

Numa perspectiva de ensino de Tabela Periódica nas aulas de química do Ensino Médio, propomos um jogo didático que chamamos de Corrida Periódica, viabilizando facilitar a apropriação da linguagem química pelos estudantes. Escolhemos um tipo de jogo que julgamos ser conhecido pelos estudantes desta faixa etária, assim como a presença de uma afinidade maior por eles, e esta decisão foi tomada após conversas com o professor e estudantes.

A Corrida Periódica é um jogo que propõe aos estudantes analisar a Tabela Periódica (TP) para desmistificar os signos da linguagem presente na TP, a partir da classificação periódica, a origem da nomenclatura e propriedades periódicas dos elementos químicos, 
possibilitando a apropriação da simbologia característica deste conteúdo.

É utilizado um painel (figura 1) com três percursos, cada um representando uma temática do conteúdo (classificação periódica dos elementos químicos na cor vermelha, origem da nomenclatura dos elementos químicos na cor azul e propriedades periódicas dos elementos químicos na cor verde), um dado de 06 (seis) faces (figura 2) representando as 3 (três) temáticas da TP mencionadas anteriormente com suas respectivas cores, repetindo 2 (duas) vezes cada temática. O jogo contém também 12 (doze) minicarros (três na cor branca, três na cor lilás, três na cor preta e três na cor laranja) que representará as equipes jogadoras nos percursos, 75 (setenta e cinco) cartas de perguntas, sendo 25 (vinte e cinco) para cada tema (figura 3 e 5), e 15 cartas PASSA A VEZ como mostra a figura 4 e 5 . Para a confecção do jogo foram necessários folhas de emborrachado vermelho, azul, verde e preto, papel cartão e impressora.

Figura 1: Painel com os três percursos do jogo.

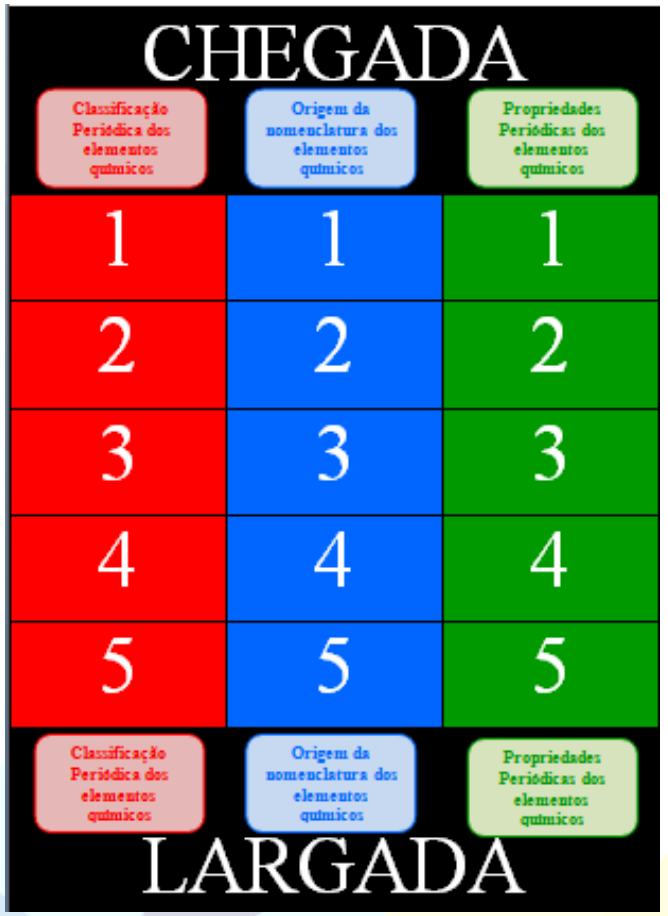

Figura 2: Dado com as temáticas da TP.

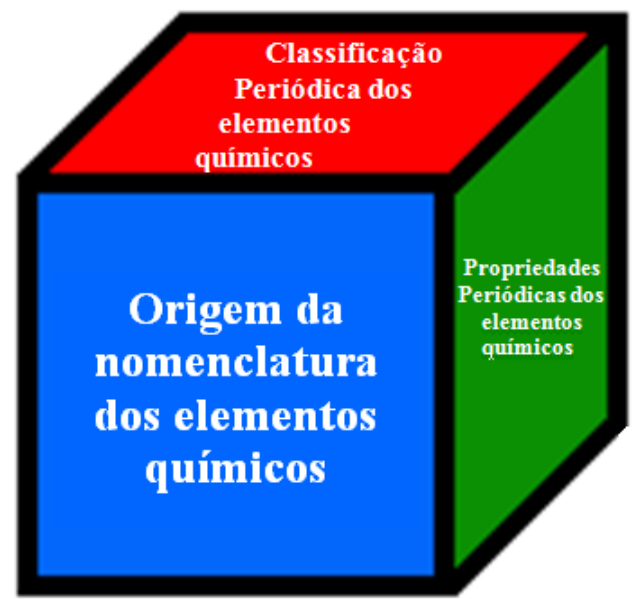

Fonte: Própria

Fonte: Própria

Figura 3: Cartas de perguntas. Fonte: Própria

\begin{tabular}{|c|c|c|}
\hline $\begin{array}{l}\text { Qual o símbolo do } \\
\text { metal localiza do } \\
\text { no } 5^{\circ} \text { período e no } \\
\text { gupo } 13 \text { ? }\end{array}$ & $\begin{array}{l}\text { Qual elemento foi } \\
\text { nomeado em } \\
\text { homenagem ao } \\
\text { cientista Emest O. } \\
\text { Laurence? }\end{array}$ & $\begin{array}{l}\text { Qual o elemento } \\
\text { mais eletropositivo } \\
\text { da tabela } \\
\text { periódica? }\end{array}$ \\
\hline R: In (Indio) & R: Laurêncio (Lr) & R: Frâncio (Fr) \\
\hline
\end{tabular}

Figura 4: Cartas PASSA A VEZ. Fonte: Própria 


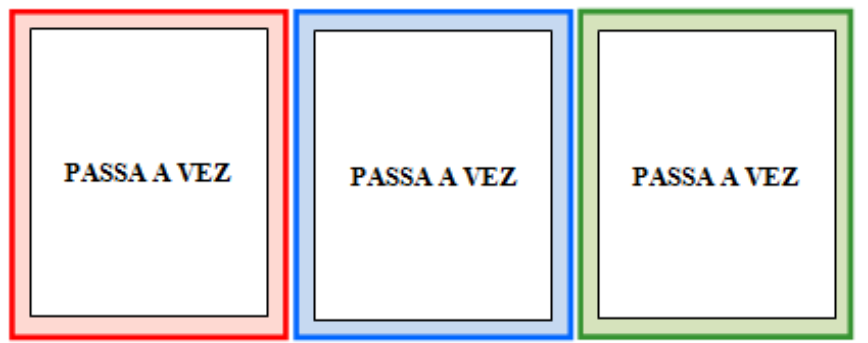

Figura 5: Verso das cartas de perguntas e das cartas PASSA A VEZ. Fonte: Própria
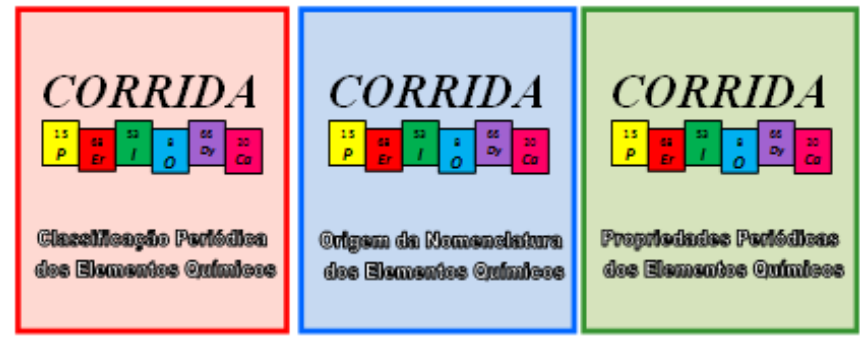

As regras do jogo didático Corrida Periódica são descritas no quadro abaixo (Quadro 1):

Quadro 1: Regras do jogo didático Corrida Periódica. Fonte: Própria.

1. Dividir a turma em 2 (duas) a (quatro) equipes;

2. Cada equipe deverá escolher 01 (um) representante;

3. Para sortear a equipe que iniciará o jogo, todos os representantes tiram "0 (zerinho) ou 1(um)";

4. Cada equipe terá 03 (três) minicarros, ao qual cada um deve estar posicionado em um percurso do jogo e todos eles devem iniciar na faixa preta de largada;

5. $\mathrm{O}$ (a) representante da equipe que iniciará o jogo deve lançar o dado;

- O dado irá mostrar uma temática da Tabela Periódica e o(a) professor(a) mediador(a) da atividade deve retirar 01 (uma) carta do maço de cartas do tema mostrado no dado.

* Se a carta mostrar passa a vez, a partida é repassada ao próximo grupo no sentido horário;

* Se a carta mostrar uma pergunta, a mesma é lida em voz alta pelo(a) professor(a) e a equipe jogadora da vez terá 01 (um) minuto para responder. $\mathrm{O}$ (a) professor(a) julgará a resposta como certo ou errado e retira a ficha do jogo. Se a resposta à pergunta for considerada correta, a equipe jogadora avança 01 (uma) casa no percurso da temática e aguarda novamente sua vez de jogar. Se a resposta for considerada errada, a equipe jogadora volta 01 (uma) casa no percurso da temática e aguarda novamente sua vez de jogar, o professor nesse caso pedirá as outras equipes para responder, caso acertem podem avançar 01 (uma) casa no percurso e o jogo se decorrerá normalmente, e se nenhuma equipe souber, o professor poderá discutir a resposta correta. Quando um dos maços de perguntas terminar, os cartões retirados voltam para o jogo.

6. Ganha o jogo a equipe que chegar primeiro com 01 (um) de seus 03 (três) minicarros na casa CHEGADA. OBS: Em todo momento do jogo as equipes participantes podem utilizar a Tabela Periódica para auxiliar nas respostas.

\section{RESULTADOS E DISCUSSÃO}

Na aplicação do jogo didático Corrida Periódica, fizemos uso do diário de campo e a partir dele podemos descrever que os estudantes foram bastante participativos durante toda a atividade, interagindo com os colegas de equipe e tentando solucionar as questões dispostas pelo jogo, caracterizando o conceito de interação importante no processo de aprendizagem defendido por Vygotsky, incluindo também a ocorrência da ZDP. Abaixo apresentamos algumas imagens do momento da aplicação do jogo (Figura 6). 
Figura 6: Aplicação do jogo didático Corrida Periódica em sala de aula. Fonte: Própria.

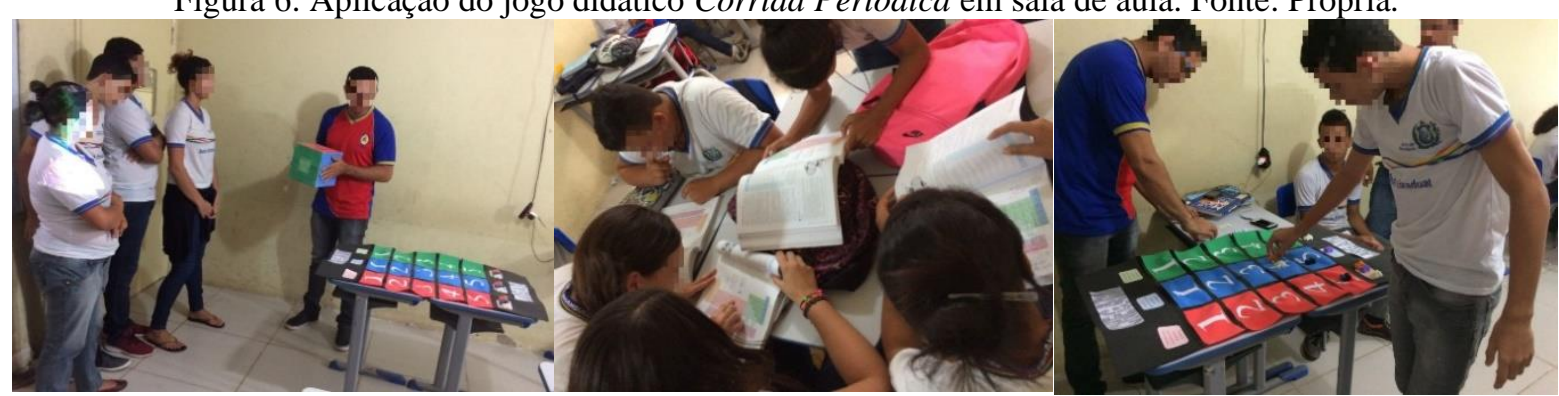

Inicialmente, quando o professor apresentou o jogo algumas falas dos estudantes se sobressaíram:

Estudante 1: "Vale ponto?"

Estudante 2: "Vou ganhar o que?"

Notamos logo de início que os estudantes se surpreenderam com a atividade e por ser algo diferente do que viam nas aulas, não pensaram ser a aula de fato e sim uma atividade apenas de caráter avaliativa, perguntando assim qual nota valeria pela participação. O professor se expressou de maneira objetiva, respondendo que tudo é negociável, mostrando para os estudantes a importância da participação para o aprendizado de cada um e que a avaliação é feita diariamente em todas as aulas e não apenas nas provas de final de bimestre e o importante naquele momento era a participação de todos para favorecer a apropriação da linguagem científica do conteúdo abordado no jogo.

No decorrer do jogo percebemos que os estudantes conheciam apenas os elementos químicos mais vistos em seu dia-a-dia, como o oxigênio, cloro, sódio etc, contudo não sabiam sua localização na Tabela Periódica e nem os símbolos corretos deles. O jogo permitiu então essa possibilidade de conhecer a localização dos elementos químicos, assim como identificar além dos símbolos e nomenclatura, os números atômicos e de massa, uma vez que era permitido o uso da Tabela Periódica durante o jogo. Desta forma, os estudantes conseguiram ter o contato direto e a todo momento com a Tabela Periódica, a conhecendo de fato e desmistificando aos poucos a linguagem presente nela, compreendendo que ela não é apenas um aglomerado de símbolos, e sim um conhecimento primordial da química, embasados em estudos e que contribui efetivamente para diversos conteúdos químicos.

Além disso, o jogo contribuiu para a compreensão da origem das nomenclaturas e simbologias, aspectos esses que geralmente não são ensinados na escola. Outra característica abordada foram as propriedades periódicas, na qual observamos as maiores dificuldades, tendo estudantes que perguntaram até o que eram essas propriedades como mostrado na fala a seguir. 
Estudante 3: "O que significa afinidade?"

Como o jogo permitia ao professor a resolução de perguntas que as equipes não conseguiam responder, houve momentos de esclarecimentos de dúvidas e ensinamentos de tópicos que antes os estudantes não sabiam, o que foi muito satisfatório e positivo para a construção de conhecimento e para a apropriação da linguagem científica do conteúdo.

Com os questionamentos da entrevista pudemos observar as percepções dos estudantes perante a vivência do jogo. As questões e as respostas dadas pelos estudantes das duas turmas são mostradas abaixo.

1. Vocês gostaram do jogo?

Turma 1- Sim, foi bom de jogar, bem divertido.

Turma 2- Foi muito bom, divertido e com a competição nos fez prestar atenção pra responder certo e ganhar o jogo.

2. Em relação ao conteúdo, vocês aprenderam mais? Se sim, gostaram de aprender assim?

Turma 1- Sim. Foi muito bom e descontraído.

Turma 2- Sim. Foi bem diferente aprender brincando, coisa que nunca vimos muito na aula.

3. Qual a contribuição do jogo para vocês?

Turma 1- Foi bom porque trabalhamos em grupo, um ajudando o outro e assim aprendemos mais sobre a Tabela Periódica.

Turma 2- Melhoramos nosso conhecimento e aprendemos mais de forma divertida.

4. Em relação ao conteúdo de Tabela Periódica, vocês costumavam usar o nome dos elementos químicos ou a simbologia química deles?

Turma 1- Os dois, tanto a nomenclatura quanto os símbolos dos elementos.

Turma 2- Usávamos mais o nome dos elementos, porque nem sabíamos muito os símbolos, mas agora conhecemos mais.

5. Se vocês ouvirem o nome de algum elemento químico vocês irão saber o símbolo químico dele? E ao contrário, se vocês ouvirem o símbolo, vocês irão saber o nome do elemento químico?

Turma 1- Mais ou menos, apenas os elementos químicos mais conhecidos por nós e tem alguns que confundimos também.

Turma 2- Sabemos só de alguns e com o jogo aprendemos outros que antes não sabíamos.

6. Se existisse apenas o nome dos elementos sem quaisquer simbologias, a compreensão do conteúdo seria como?

Turma 1- Seria mais difícil, porque com os símbolos é mais fácil a identificação na Tabela 
Periódica, e até na fala também quando alguém fala o símbolo já nos remete ao elemento a que está falando.

Turma 2- Bem mais difícil. Com os símbolos fica mais fácil de aprender e imaginar os nomes dos elementos.

Com as entrevistas, conhecemos a versão do alunado perante o jogo e notamos o quanto contribuiu para o desenvolvimento de habilidades como a interação e o trabalho em equipe e para o conhecimento no conteúdo na desmistificação da linguagem científica escolar da Tabela Periódica. Observamos também que antes do jogo os estudantes não conheciam a importância da simbologia deste conteúdo e reconheceram que com a apropriação da linguagem a aprendizagem dos outros conceitos é facilitada. Neste sentido, Aquino, Santos e Silva (2012) relatam que a simbologia apresentada no conteúdo de Tabela Periódica tem valiosa importância no processo de construção de representações de substâncias químicas e de moléculas, isto é, para apreender sobre as fórmulas químicas se faz necessário o conhecimento prévio dos símbolos químicos.

\section{CONCLUSÕES}

A linguagem química descreve aspectos essenciais para os conhecimentos químicos, e trata-la em sala de aula em um contexto que engloba não apenas a simbologia, mas também os seus significados e conceitos que dependem dela, permite uma compreensão mais sólida dos conteúdos. Nesse sentido, não há espaço para uma abordagem tradicional contínua na prática docente, uma vez que a reprodução de conhecimento e memorização de fórmulas, representações e conceitos não viabiliza uma construção de conhecimento repleta de significações. Nesse caso, trazer atividades como o jogo didático proporciona um ambiente propício a essa apropriação da linguagem científica escolar na disciplina de química, assim como o aprendizado dos significados que desmistificam a linguagem química dos conteúdos, mais especificamente em Tabela Periódica como discutido no presente estudo.

Os resultados obtidos mostraram que os estudantes mesmo já tendo estudado os conteúdos, não compreendiam o uso da Tabela Periódica, incluindo sua simbologia, suas origens e a importância dela para outros conteúdos químicos. Com o jogo, os estudantes adquiriram momentos de socialização por meio do trabalho em equipe, o que possibilitou conhecer os elementos químicos mais profundamente, por meio da história de suas origens, propriedades, particularidades e curiosidades, dando significado a simbologia que antes não era dada a devida atenção. Portanto, podemos afirmar o jogo didático proposto e utilizado nesta pesquisa foi fundamental no processo de apropriação da simbologia do conteúdo de Tabela 
Periódica.

\section{REFERÊNCIAS}

ANDRADE NETO, A. S.; RAUPP, D.; MOREIRA, M. A. A evolução histórica da linguagem representacional química: uma interpretação baseada na Teoria dos Campos Conceituais. In: Encontro Nacional de Pesquisa em Educação em Ciência, 7, 2009, Florianópolis. Anais do Encontro Nacional de Pesquisa em Educação em Ciência. Florianópolis: Universidade Federal de Santa Catarina, 2009.

AQUINO, G. B.; SANTOS, E. P.; SILVA, B. C. F. Tabela Periódica e Notações Químicas: análise das dificuldades discentes na compreensão da linguagem química. Colóquio Internacional Educação e Contemporaneidade, 6, 2012, São Cristovão. Anais do Colóquio Internacional Educação e Contemporaneidade. São Cristovão: Universidade Federal de Sergipe, 2012.

DEL RE, G. Models and analogies in science. HYLE-Int. J. Philos. Chem. v. 6, n. 1, 2000, p. 5-15. Disponível em: < http://www.hyle.org/journal/issues/6/delre.pdf>. Acesso em: 23 set. 2018.

FANG, Z. The Language Demands of Science Reading in Middle School. International Journal of Science Education, v.28, n. 5. University of Florida, USA, 2006, p.491-520.

FONTANA, R.; CRUZ, N. Psicologia e trabalho pedagógico.1. ed. São Paulo: Atual Editora, 1997.

MESSEDER NETO, H. S.; MORADILLO, E. F. O jogo no ensino de química e a mobilização da atenção e da emoção na apropriação do conteúdo científico: aportes da psicologia histórico-cultural. Ciênc. Educ., Bauru, v. 23, n. 2, 2017, p. 523-540.

MIRANDA, S. No fascínio do jogo, alegria de aprender. Ciência Hoje, v.28, 2001, p.64-66.

OLIVEIRA, M. K. Vygotsky: aprendizado e desenvolvimento, um processo sóciohistórico. 4. ed. São Paulo: Scipione, 2002.

OLIVEIRA, O. M. M. F; SCHLÜNZEN JUNIOR, K.; SCHLÜNZEN, E. T. M. Química. Coleção Temas de Formação; v. 3. São Paulo: Cultura Acadêmica: Universidade Estadual Paulista: Núcleo de Educação à Distância, 2013.

PIOVESAN, S. D. Sistema imersivo para inclusão de pessoas com deficiência intelectual no mercado de trabalho. 2015, 132 f. Tese (Doutorado em Informática na Educação) Universidade Federal do Rio Grande do Sul, Porto Alegre, 2015.

SEPULVEDA, C.; EL-HANI, C. N. Apropriação do discurso científico por alunos protestantes de biologia: uma análise à luz da teoria da linguagem de Bakhtin. Rev. Investigações em Ensino de Ciências, v. 11, n. 1, 2006, p. 29-51.

VYGOTSKY, L. S. A formação social da mente: o desenvolvimento dos processos psicológicos superiores. 7. Ed. São Paulo: Martins Fontes, 2007. p. 51-107. 
Pensamento e linguagem. 4. ed. São Paulo: Martins Fontes, 2008. 